Publisher: ELSEVIER SCIENCE BV, PO BOX 211, 1000 AE AMSTERDAM, NETHERLANDS

Subject Category: Biochemical Research Methods; Chemistry, Analytical

DOI: 10.1016/j.chroma.2004.03.015

http://www.sciencedirect.com/science? ob=ArticleURL\& udi=B6TG8-4C4BMVB-

2\& user $=2347467 \&$ coverDate $=06 \% 2 F 04 \% 2 F 2004 \&$ alid $=1140637057 \&$ rdoc $=5 \&$ fmt $=$ high \& orig $=$ search \& cdi $=5248 \&$ sort $=\mathrm{r} \& \mathrm{st}=13 \&$ docanchor $=\& \mathrm{ct}=13 \&$ acct=C000057013\& version $=1 \&$ urlVersion= $\underline{0 \& \text { userid }=2347467 \& \mathrm{md} 5=f 0 c c c d a 8441500489 \mathrm{bb} 9 \mathrm{dc} 5230 \mathrm{a} 19 \mathrm{cb} 7}$

\title{
USE OF SUPERHEATED LIQUIDS FOR THE EXTRACTION OF NON-VOLATILE COMPOUNDS FROM WOOD: HPLC STUDIES
}

\author{
J. González-Rodríguez ${ }^{1}$, P. Pérez-Juan ${ }^{2}$ and M.D. Luque de Castro ${ }^{3^{*}}$ \\ 1 R\&D Department Pérez Barquero, S.A. Avda. de Andalucía, 27, E-14550, \\ Montilla, Córdoba, Spain. Fax: 957 650208, E-mail: barquero@,fiab.es \\ ${ }^{2}$ LIEC, Laboratory and Enologic Research of Castilla, Polígono industrial, calle XV, \\ parcela R-113, E-13200, Manzanares (Ciudad Real), Spain. Phone: 34-926647115, \\ E-mail: liec@erasnet.net \\ 3 Department of Analytical Chemistry, University of Córdoba, Campus of \\ Rabanales, Annex C-3, E-14071, Córdoba, Spain. E-mail: qallucam@uco.es; \\ Fax:+34 957218615
}

A study of the extraction of oak wood compounds using superheated waterethanol mixtures ranging from 10 to $60 \%$ ethanol is reported. Identification and characterization of the extracted compounds have been made by high performance liquid chromatography. The extraction has been performed using the static mode by single or repetitive cycles. The variables affecting the extraction process have been studied and their optimum values established (extraction time: $50 \mathrm{~min}$; pressure: $40 \mathrm{~atm}$; extraction temperature: $180^{\circ} \mathrm{C}$ ). The study allows to compare the non-volatile polyphenol fractions obtained in this way with those present in commercial samples with fully agreement between them. In addition, the method allows manipulation of the extract composition by changing the working pressure, temperature and water-ethanol ratio.

Keywords: solid-liquid extraction, liquid chromatography, oak wood, superheated liquids 


\section{Introduction}

Some kinds of wines and spirits are aged in wood barrels for long periods in order to obtain their characteristic flavour and smell. Oak is the wood most commonly used for this type of aging. It is composed mainly of polysaccharides (cellulose and hemicellulose), lignin and small quantities of phenols and tannins, basically ellagitannins [1].

The lignin leaches out from the wood in an alcoholic medium forming ethanol-lignin complexes that are later broken down, yielding aromatic aldehydes. These substances undergo oxidation reactions generating aromatic acids. Vanillin and syringaldehyde are the main aldehydes in spirits aged in oak, though large amounts of cinnamic aldehydes (coniferaldehyde and synapaldehyde) and their respective acids forms (vanillic and syringic acids for the first ones and ferulic and synapic acids for the second ones), can be found [2]. In addition to these substances formed from lignin hydrolysis by alcohol, other phenolic compounds present in wood that leach into the water/ethanol mixture during aging have also been identified -namely, scopoletin [3], gallic and ellagic acids and various hydrolyzed tannins, which may subsequently undergo hydrolysis to form the respective acids referred above [4]-. The concentrations of these substances in aged beverages are correlated with the type of oak used and aging time.
During the manufacture of the barrels, a heat treatment of wet oak staves is needed to facilitate stave assembly, after which a later toasting is performed. During these processes, a variety of hydrothermolysis and pyrolisis reactions take place, producing the degradation of biopolymers such as lignin, polyosides, polyphenols and lipids. The thermodegradation of lignin yields volatile phenols and phenolic aldehydes, mainly, and some phenolic alcohols [5-9]. The aldehydes come from the thermal degradation of the terminal monomeric units of lignin: the cinnamic aldehydes become benzoic aldehydes, and these are oxidized to phenolic acids. The last ones yield volatile phenols by decarboxylation. Toasting can also produce phenyl ketones and some esters from phenolic acids.

Both processes, alcoholic hydrolysis and thermal treatment, are the main responsible for the presence of the substances coming from the wood into the water/ethanol mixture.

The extracts from oak wood obtained by using superheated ethanol/ water mixtures have been studied by the authors in a previous work [10]. When GC/MS was used volatile compounds found in the extracts, obtained using 60:40 ethanol/water mixtures at $200^{\circ} \mathrm{C}$ and $40 \mathrm{~atm}$ yielded a composition similar to that found in commercial extracts obtained by the conventional techniques using organic solvents and those appeared in the 
literature. The extraction process thus developed is being patented at present [11].

The objective of the present work was the study of the non volatile fraction of these extracts obtained under subcritical conditions and the comparison of this fraction with both the commercial ones and those in the literature.

\section{Experimental}

\section{Instruments and apparatus}

The laboratory-made extractor used, shown in Fig. 1, consists of the following parts: a Knauer 64 high pressure pump (Knauer, Berlin, Germany), used to propel the extractant liquid through the system; a stainless steel cylindrical extraction chamber $(150 \mathrm{x} 11 \mathrm{~mm}$ id, $14 \mathrm{ml}$ internal volume) which was closed with screws at both ends in order to permit its filling with extractant and emptying of the extract. The screw caps also contained stainless steel filters plates ( $2 \mathrm{~mm}$ thick, and $6.35 \mathrm{~mm}$ i.d.) to ensure the wood chips remained in the extraction chamber. This chamber, with a stainless steel preheater was located in a gas chromatograph oven (HP 5720A, Hewlett-Packard, Wilmington, DE, USA) used as heating source and designed to work up to $400^{\circ} \mathrm{C}$. A loop made from 1-m length stainless-steel tubing and cooled with water at room temperature, was used to cool the extract from the oven to a temperature close to $25^{\circ} \mathrm{C}$. A pressure needle valve coupled to the outlet of the cooler and a selecting valve located between the high-pressure pump and the oven allowed flushing of the extract with $\mathrm{N}_{2}$ after extraction.

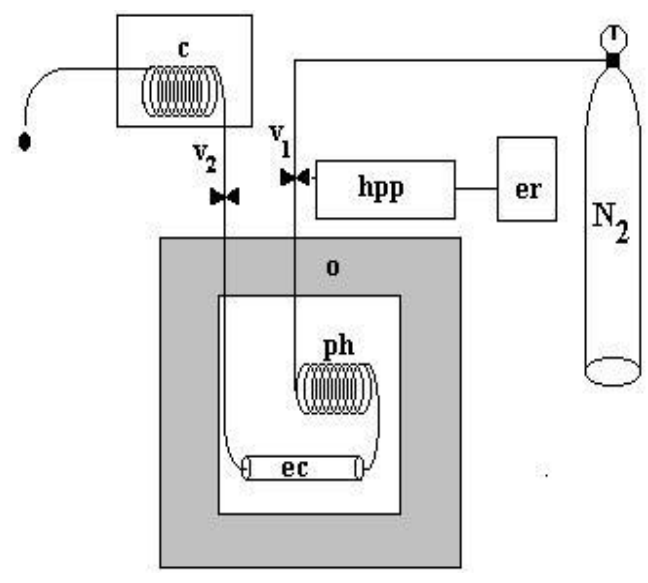

Figure 1. Extraction system. hpp: high pressure pump, er: extractant reservoir, ph: pre-heater, ec: extraction cell, o: oven, c: cooler, $\mathrm{v}_{1}=$ selection valve, $\mathrm{v}_{2}=$ restriction valve.

The analyses of the extracts were performed using a modular 1100 Hewlett-Packard liquid chromatograph (Pittsburg, PA, USA), consisting of a G1311A high pressure quaternary pump, a G1322A vacuum degasser, a 7725 Rheodyne high-pressure manual injection valve (HPIV) and a G1315A diode array detector.

All the extracts were centrifuged using a Selecta (Barcelona, Spain) Mixtasel centrifuge and filtered using $0.45 \mu \mathrm{m}$ Minisart filters from Sartorius (Göttingen, Germany). A vacuum pump (Vac Elut SPS 24, Varian, P.S. 
Analytical, England) was used for filtering the HPLC solvents. Statistical treatments were made using Statgraphics $^{\mathrm{TM}}$ plus 2.1. for Windows.

\section{Reagents and solutions}

Wood chips of American oak were obtained from a barrel shop in Montilla (Córdoba, Spain). Ethanol 96\% (v/v) PA from Panreac (Barcelona, Spain) and distilled water were used for preparing the water-alcohol mixtures used as extractant with ethanol content from 0 to $60 \%$. Diethyl ether and ethyl acetate used in extractions were from Panreac. (+)-catechin, coniferaldehyde, syringaldehyde, vanillin, sinapaldehyde and $\mathrm{m}$-hydroxybenzoic, gallic, protocatechuic, p-hydroxybenzoic, vanillic, caffeic, syringic, $p$-coumaric, ferulic, $\alpha$ hydroxycinnamic and chlorogenic acids used as chromatographic standards were from Sigma-Aldrich (St. Louis, USA) as well as picolinic acid ethyl ester used as internal standard in the case of exhaustive extraction. Scopoletin was purchased from Merck (Darmstadt, Germany). Solutions of methanol, acetic acid (both HPLC grade and supplied by Merck) and ultrapure water at $\mathrm{pH} 3$ were used as mobile phases. Methanol and ultrapure water at $\mathrm{pH} 7.0$ were used for conditioning and regeneration of the chromatographic column. Ultrapure water obtained from a Millipore (Bedfore, MA, USA) Milli-Q plus system was also used. The nitrogen used for dragging the extract from the extraction cell and for drying extracts was supplied by Air-Liquide (Paris, France).

\section{Procedures}

\section{Subcritical extraction}

The sample cell in Fig. 1 was filled with $1.5 \mathrm{~g}$ of wood chips, and two pieces of Albet 235 filter paper were inserted at both ends of the cell to prevent frit from clogging. After assembling the extraction cell in the oven, this was brought up to the working temperature $\left(200^{\circ} \mathrm{C}\right)$ and pressurised up to 40 atm with wateralcohol solution, maintaining valve $\mathrm{v}_{2}$ closed. Once the system was pressurised, valve $\mathrm{v}_{1}$ was closed and a static extraction was developed for 60 min. After this, $v_{1}$ was turned to the open position to allow nitrogen to flow through the cell by opening valve $\mathrm{v}_{2}$; then, collecting the extract in a vial at room temperature.

\section{Sample preparation}

The subcritical and commercial extracts were fractionated by liquid-liquid extraction with diethyl ether and ethyl acetate. The organic fractions were mixed, dried and reconstituted in $1 \mathrm{ml}$ of methanol. They were filtered using a $0.45 \mu \mathrm{m}$ filter before injecting.

\section{Chromatographic separation and detection}

The separation both of the extracts and the standard solutions was performed on a $250 \mathrm{~mm} \mathrm{x} 4.6 \mathrm{~mm} \mathrm{id,} 5 \mu \mathrm{m}$ particle, Hypersil ODS column (Supelco, Bellefonte, PA, USA) 
protected with a precolumn of the same material and using an injection volume of $20 \mu \mathrm{l}$. The program of the gradient elution is shown in Table 1 with a mobile phase A consisting of 10:90 methanol/water and a mobile phase B consisting of $1: 1 \mathrm{methanol} /$ water both corrected at $\mathrm{pH} 3$ by using the proper amount of acetic acid. Absorption wavelengths were set at 280 and 310 $\mathrm{nm}$ and the UV spectra in the range 220-360 nm was also recorded. Chromatographic peaks were identified by comparing their retention times and UV spectra with those of the reference compounds (Fig. 2).

Table 1. Flow rate and gradient program for the elution of the target compounds

\begin{tabular}{lcccccccccc}
\hline $\mathrm{t}(\min )$ & 10 & 20 & 30 & 40 & 50 & 60 & 70 & 80 & 90 & 100 \\
\hline $\mathrm{A}(\%)$ & 95 & 90 & 85 & & & 80 & 70 & 45 & \\
\hline $\mathrm{B}(\%)$ & 5 & 10 & 15 & & & 20 & 30 & 55 & \\
\hline $\mathrm{F}(\mathrm{ml} / \mathrm{min})$ & 1 & & 0.4 & & & & 1 & 0.8 \\
\hline
\end{tabular}
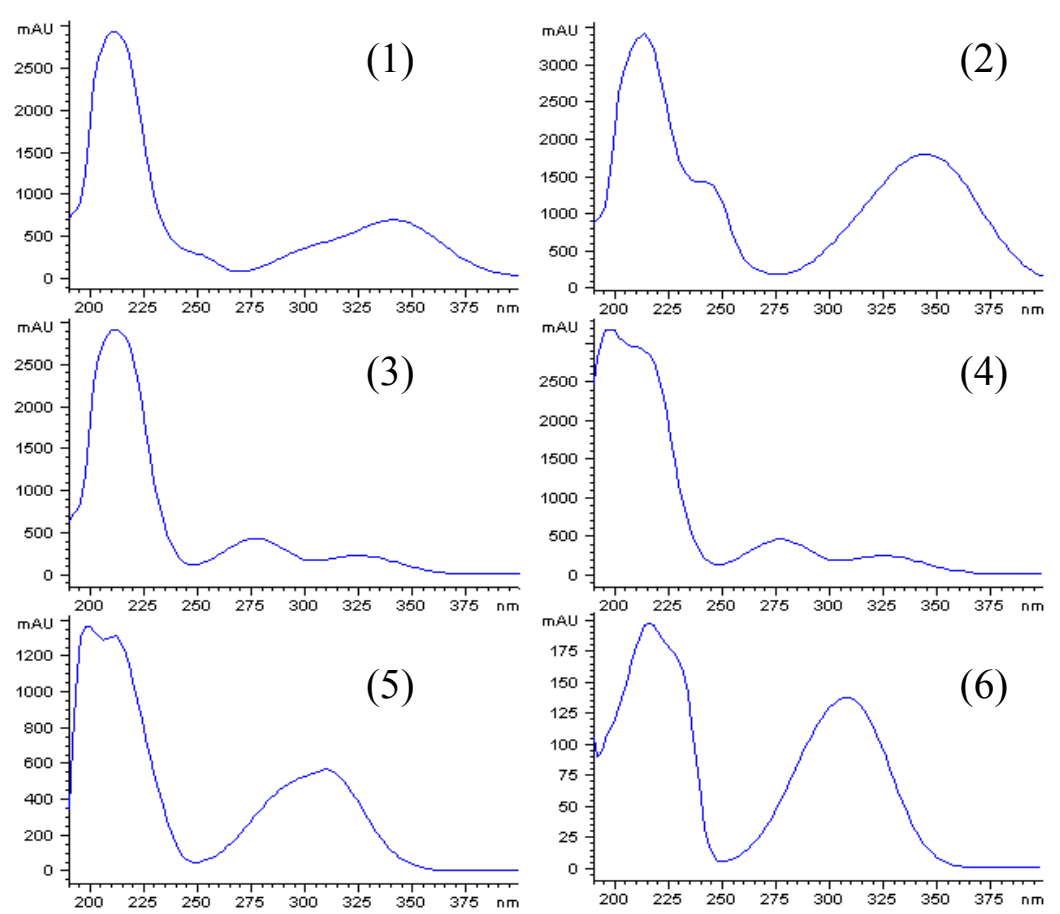

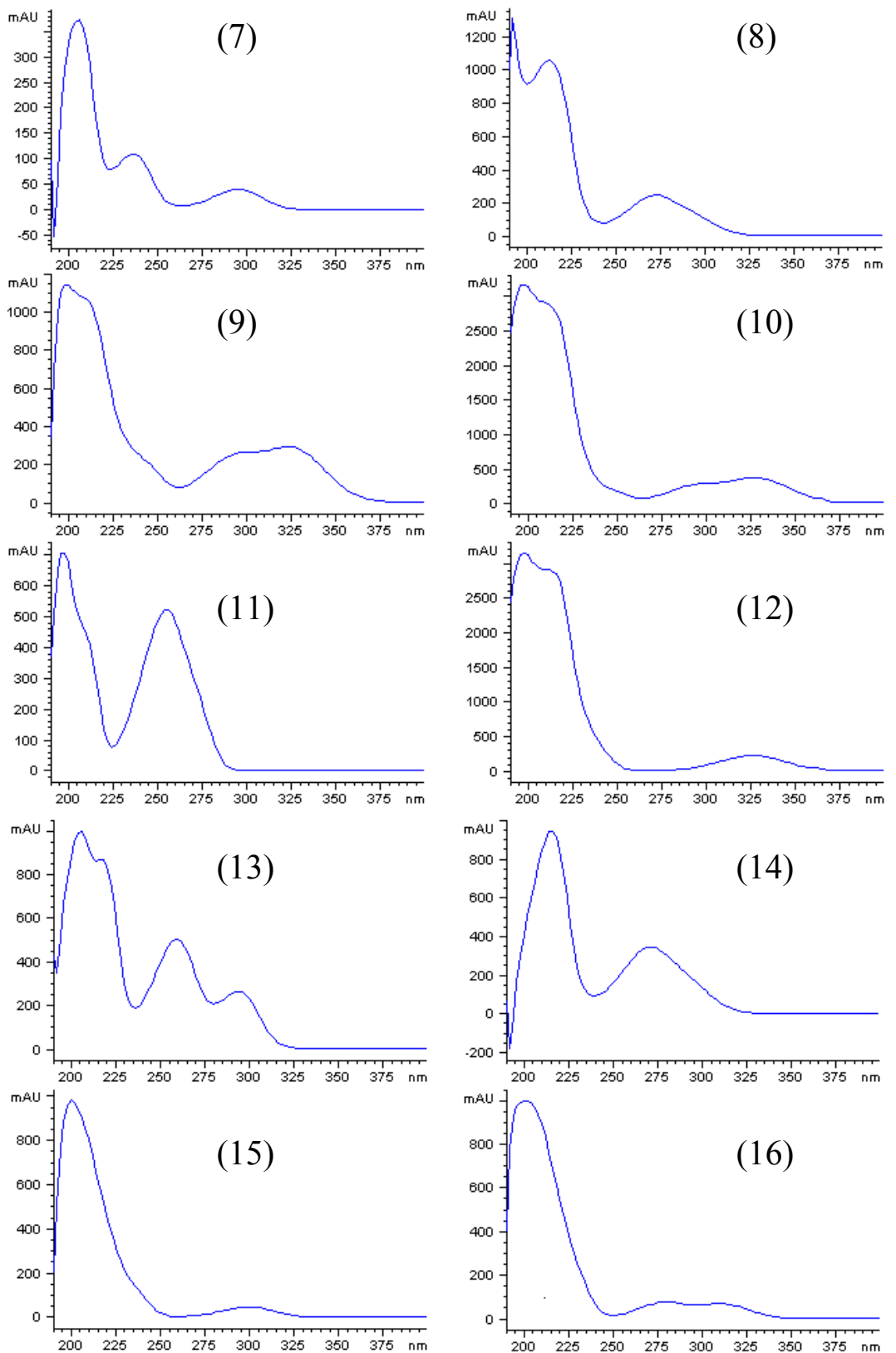


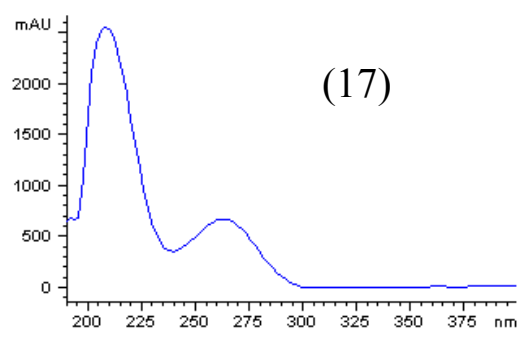

Figure 2. UV spectra of the compounds found in commercial and subcritical extracts: 1. coniferaldehyde, 2. sinapaldehyde, 3. scopoletin, 4. $\alpha$-hydroxycinnamic acid, 5. pcoumaric acid, 6. syringaldehyde, 7. syringic acid, 8. m-hydroxybenzoic acid, 9. caffeic acid, 10. chlorogenic acid, 11. p-hydroxybenzoic acid, 12. (+)-catechin, 13. protocatechuic acid, 14. gallic acid, 15. vanillic acid, 16. vanillin, 17. ferulic acid.

\section{Results and Discussion}

A static approach was tested for the extraction of compounds from wood in order to enhance the sample-extractant contact, thus favouring the attainment of the partition equilibrium.

\section{Optimisation of Variables}

The variables affecting subcritical extraction were studied in order to maximise the yield of compounds extracted from wood in a time as short as possible. With this aim, a multivariate approach was used for optimising the physical variables affecting the extraction, and a univariate approach was used for studying the influence of the ethanol percent in the extraction mixture.

The range over which the variables were studied and the optimum values found are given in Table 2.

A multivariate approach was used for the optimisation of the extraction time and temperature within the ranges 10-75 $\mathrm{min}$ and $80-300{ }^{\circ} \mathrm{C}$, respectively, using the chromatographic areas of three outstanding compounds characteristic of this kind of wood (namely, vanillin, gallic acid and syringaldehyde) as dependent variable.

Table 2. Results of the optimisation study

\begin{tabular}{lll}
\hline Variable & $\begin{array}{l}\text { Tested } \\
\text { range }\end{array}$ & $\begin{array}{l}\text { Optimum } \\
\text { value }\end{array}$ \\
\hline $\begin{array}{lll}\text { Chemical } \\
\text { EtOH }(\% \mathrm{v} / \mathrm{v})\end{array}$ & $0-60$ & 60 \\
$\begin{array}{l}\text { Physical } \\
\begin{array}{l}\text { Extraction time } \\
(\text { min) }\end{array}\end{array}$ & $10-75$ & 50 \\
$\begin{array}{l}\text { Extraction } \\
\text { temperature }\left({ }^{\circ} \mathrm{C}\right)\end{array}$ & $80-300$ & 180 \\
$\begin{array}{l}\text { Sample weight } \\
\text { (g) }\end{array}$ & - & 1.5 \\
Pressure (atm) & - & 40 \\
\hline
\end{tabular}


The results from the ANOVA studies and the response surfaces for the experimental design obtained were statistically equal in all cases.

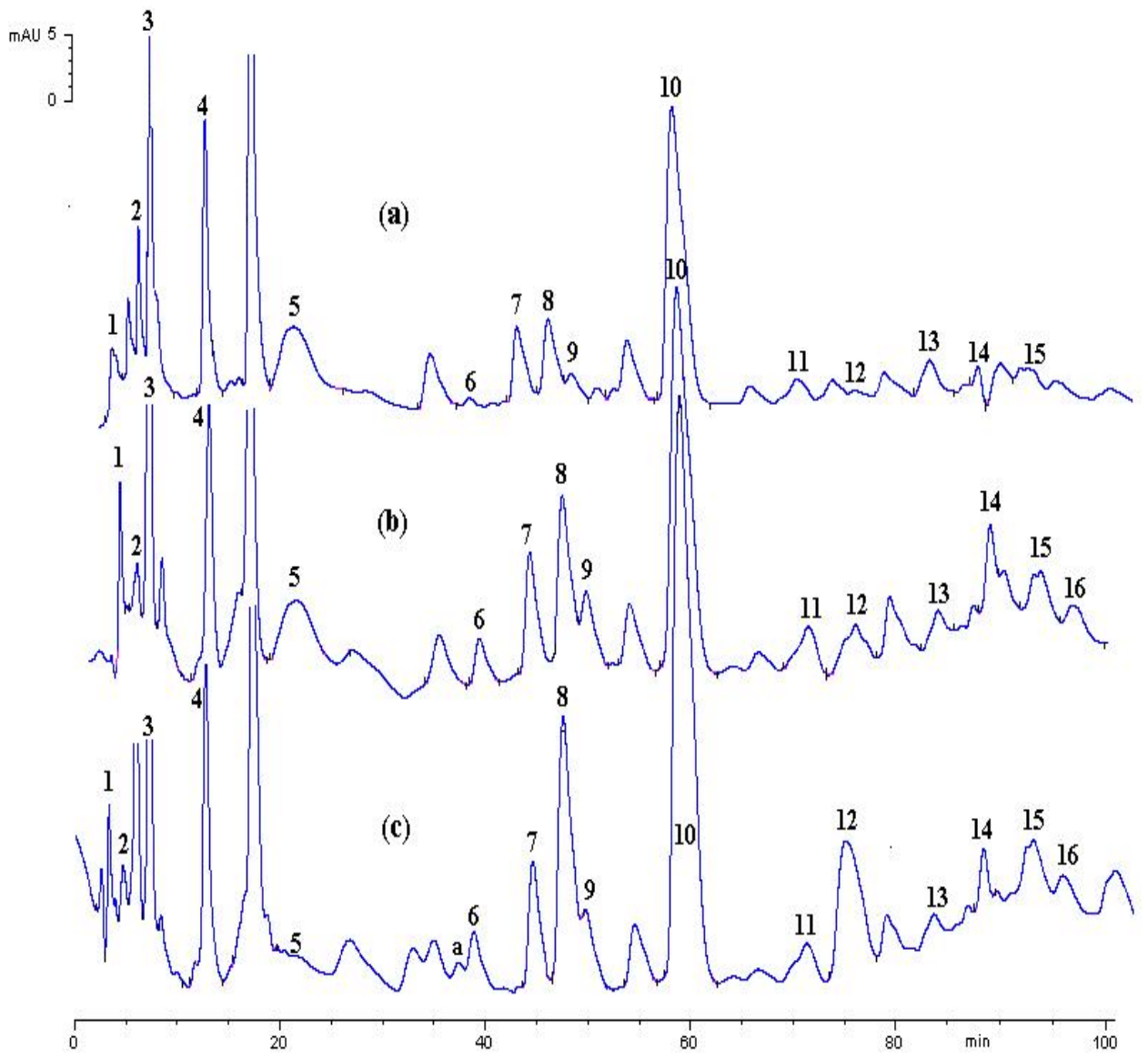

Figure 3. Chromatograms provided by extract from wood. Study of degradation at (a) $180^{\circ} \mathrm{C}$, (b) $250^{\circ} \mathrm{C}$, (c) $300^{\circ} \mathrm{C}$. Compounds: (1) gallic acid, (2) protocatechuic acid, (3) p-hydroxybenzoic acid, (4) syringic acid, (5) syringaldehyde.

The signal increased when the time and temperature were increased but with a higher effect from the former. A time of $50 \mathrm{~min}$ and a temperature of
$180{ }^{\circ} \mathrm{C}$ were selected as optimum. At temperatures higher than $180^{\circ} \mathrm{C}$ the majority of the studied compounds begin to decompose with the exception 
of some of them such as syringaldehyde and gallic, protocatechuic, p-hydroxybenzozic and syringic acids which increase their concentrations, as shown in the chromatogram in Figure 3. The effect of high temperatures -above $200^{\circ} \mathrm{C}-$ gave rise to decarboxylation and breaking of lignin aryl ether bonds, which cause the formation of cinnamic aldehydes. At higher temperatures an oxidative cleavage of the double C-C bond of these aldehydes could happen yielding benzoic aldehydes and syringaldehyde. This phenomenon could explain the increasing of syringaldehyde and p-hydroxybenzoic and syringic acids (coming from oxidation of benzoic aldehydes) and gallic acid could come from the splitting of complex structures and from a stronger lignin degradation when temperature raises. This fact made that temperatures higher than $180^{\circ} \mathrm{C}$ were rejected despite some of the peaks selected for the optimisation study increased. Since the P-value in the ANOVA table is less than $0.05 \%$, there is a statistically significant relationship between the variables at $95 \%$ confidence level. The equation of the model chosen in the optimization is: Area $=$ $3679-228 T+213 t+0.975 T^{2}+1.7$ $T t-3.83 t^{2}$, where $T=$ temperature and $t=$ time.

The amount of ethanol in the extractant was studied by the univariate method in the range $0-60 \%(v / v)$. Higher concentrations were not used because $60 \%(v / v)$ ethanol is the maximum found both in the literature and commercial extracts. It was found that maximum extraction of the target compounds was achieved by increasing the ethanol concentration, as expected.

The amount of sample used was that necessary $(1.5 \mathrm{~g})$ to fill the extraction cell. The pressure was that required to maintain liquid the ethanolwater mixture. As the vapour pressures of ethanol and water at $200{ }^{\circ} \mathrm{C}$ are 30 and 20 atm, respectively, [12], a pressure of 40 atm was chosen in order to guarantee the liquid state of the extractant in all the experiments.

These parameters are very similar to that obtained in a previous work [10] in which the volatile compounds in wood were analysed using GC-FID and GC-MS, which allows to establish a compromise for the simultaneous extraction of volatile and non-volatile compounds as a function of the optimum values for the extraction of each type of compounds.

\section{Composition of the Extract}

The composition of the extract obtained using the optimum working conditions was characterized by HPLC. As can be observed in Fig. 4, the majority of compounds found in commercial samples (a) and (c) are also found in the subcritical extract (b). The compounds found both in the extracts and the commercial samples are the same as those described in the literature and their concentrations are approximately in the same ratio approximately. This allows to conclude that the extraction process using subcritical fluids is at least as effective as the extraction of wood compounds using organic sol- 
vents in order to extract volatile and non-volatile compounds from wood, used in industry at present. Average retention times of the studied compounds are summarized in Table 3.

Table 3. Retention times of the studied compounds in wood $(n=3)$

\begin{tabular}{llll}
\hline Name & $\begin{array}{l}\text { Retention time } \\
(\mathrm{min})\end{array}$ & Name & $\begin{array}{l}\text { Retention time } \\
(\mathrm{min})\end{array}$ \\
\hline m-hydroxybenzoic acid & $4.90 \pm 0.15$ & syringic acid & $49.00 \pm 0.66$ \\
\hline Gallic acid & $6.02 \pm 0.33$ & syringaldehyde & $59.03 \pm 0.36$ \\
\hline protocatechuic acid & $12.77 \pm 0.57$ & p-coumaric acid & $71.48 \pm 0.61$ \\
\hline p-hydroxybenzoic acid & $21.68 \pm 0.43$ & ferulic acid & $75.90 \pm 0.71$ \\
\hline vanillic acid & $38.96 \pm 0.36$ & coniferaldehyde & $83.71 \pm 0.52$ \\
\hline chlorogenic acid & $39.81 \pm 0.43$ & sinapaldehyde & $88.62 \pm 0.36$ \\
\hline caffeic acid & $43.68 \pm 0.61$ & $\begin{array}{l}\alpha \text {-hydroxycinnamic } \\
\text { acid }\end{array}$ & $93.38 \pm 0.65$ \\
\hline Vanillin & & scopoletin & $96.30 \pm 0.56$ \\
\hline
\end{tabular}

Table 4. Exhaustive extraction of polyphenols from wood by repetitive cycles as a function of the ethanol percentage in water

\begin{tabular}{|c|c|c|c|c|c|c|c|c|c|c|c|c|}
\hline \multirow{2}{*}{$\begin{array}{l}\text { water/ethanol } \\
(\% \mathrm{v} / \mathrm{v})\end{array}$} & \multicolumn{3}{|c|}{ cycle $1^{*}$} & \multicolumn{3}{|c|}{ cycle $2^{*}$} & \multicolumn{3}{|c|}{${\text { cycle } 3^{*}}^{*}$} & \multicolumn{3}{|c|}{ cycle $4^{*}$} \\
\hline & $\mathrm{G}$ & V & $\mathrm{S}$ & $\mathrm{G}$ & V & $\mathrm{S}$ & $\mathrm{G}$ & $\mathrm{V}$ & $\mathrm{S}$ & G & V & $\mathrm{S}$ \\
\hline $90: 10$ & 7.61 & 1.96 & 15.2 & 2.59 & 0.90 & 4.41 & 0.93 & 0.45 & 0.96 & 0.23 & 0.12 & 0.15 \\
\hline $70: 30$ & 15.35 & 5.62 & 52.6 & 4.62 & 2.19 & 14.20 & 1.87 & 1.11 & 2.35 & 0.52 & 0.45 & 0.81 \\
\hline $40: 60$ & 34.64 & 12.85 & 102.3 & 9.36 & 4.88 & 24.68 & 2.34 & 2.34 & 10.23 & 0.85 & 0.95 & 1.77 \\
\hline
\end{tabular}

* referred to picolinic acid ethyl ester used as internal standard in $\mathrm{mg} / \mathrm{l} . \mathrm{G}=$ galic acid, $\mathrm{V}=$ =vanillin,

$\mathrm{S}=$ syringaldehyde

\section{Exhaustive Extraction}

A study of exhaustive extraction of the valuable compounds in the wood sample was performed. Table 4 shows the areas obtained in the chromatograms, referred to an internal standard (picolinic acid ethyl ester), from three of the most outstanding compounds (namely, gallic acid, vanillin and syringaldehyde). The extractions were performed in four cycles using ethanol/water mixtures with a 10,30 , $60 \%$ of ethanol content. The extraction percentages for the three compounds ranged between $60-75 \%$ for the first cycle, $15-20 \%$ for the second, $5-15 \%$ for the third and $1-6 \%$ for the last. There were not significant differences for gallic acid and syringaldehyde, and the lowest yield was obtained for vanillin in all cases.

It was checked that higher concentrations of ethanol increased the extraction of these compounds. These results agree with those obtained in a previous work [10] in which the total polyphenol index was used to monitor the extraction process. 


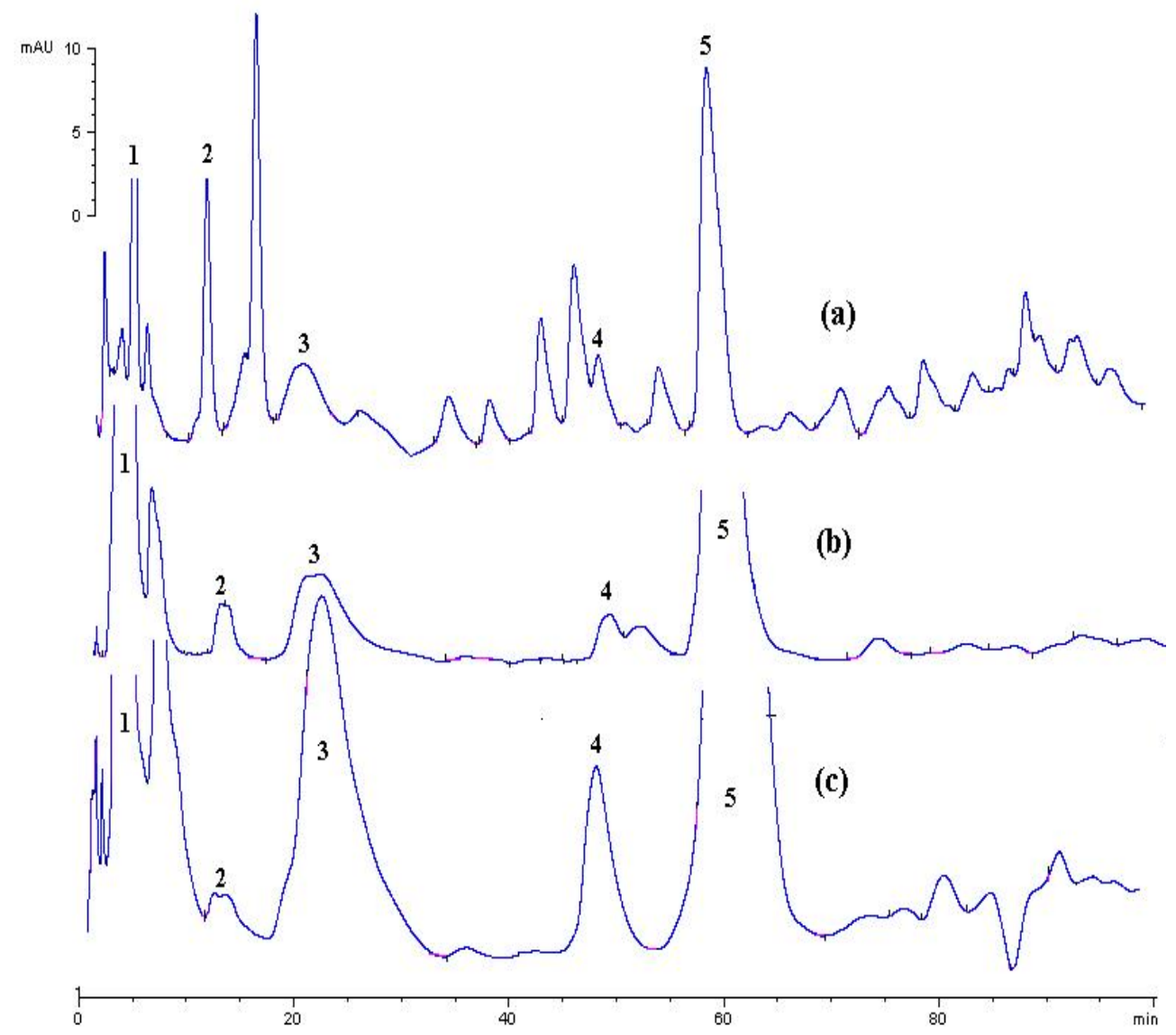

Figure 4. HPLC chromatograms of (a) and (c): commercial extracts, (b) subcritical extract. Compounds common to both chromatograms are as follows: (1) (+) catechin, (2) mhydroxybenzoic acid, (3) gallic acid, (4) protocatechuic acid, (5) p-hydroxybenzoic acid, (6) vanillic acid, (7) caffeic acid, (8) vanillin, (9) syringic acid, (10) syringaldehyde, (11) pcoumaric acid, (12) ferulic acid, (13) coniferaldehyde, (14) sinapaldehyde, (15) $\alpha$ hydroxycinnamic acid, (16) scopoletin. The Compound found only in one of the commercial extracts (a) was chlorogenic acid

\section{Changes of the extract composition} As previously observed by the authors, the proposed extraction method allows alteration of the composition of the extract by changing extraction para- meters such as temperature, extraction time and ethanol percentage in the extractant. These changes allowed the extracts to be enriched in one or several compounds. This manipulation of the 
extracts is unfeasible with the conventional method [10].

\section{Conclusions}

The objective of the present work was to check the capacity of subcritical ethanol-water for the extraction of nonvolatile characteristic polyphenols from wood; with the view of proposing a new more effective and cheaper method for obtaining the extracts used in wineries. The use of subcritical extracts presents a number of advantages as compared with conventional alternatives, namely: shorter extraction times (50 min versus 4-7 hours required by the conventional methods), an important saving of ethanol and the possibility of manipulating the composition by changing the extraction parameters (which allows the obtainment of extracts with different composition). The comparison of the HPLC chromatograms from the extract and the commercial products shows that there is an almost total coincidence between the compounds found in both. This fact together with the close coincidence of the optimum extraction parameters with those obtained for the extraction of volatile compounds makes feasible the industrial exploitation of the proposed method for the obtainment of commercial extracts. The exhaustive studies performed have shown that most of the outstanding non-volatile compounds can be extracted with only two extraction cycles in percentages ranging from 75 to $95 \%$.

\section{Acknowledgments}

The Spanish Comisión Interministerial de Ciencia y Tecnología (CICyT) is thanked for financial support (Project AGL2000-0321-P4-03). The Agriculture Chemistry Department is also thanked (particularly Dra. López Toledano) for providing standards and bibliography.

\section{Bibliography}

[1] A. Scalbert, B. Monties, J.M. Favre, Phytochemistry 27 (1988) 3483.

[2] T. Delgado, C. Gómez-Cordovés, Rev. Fr. Oenol. 107 (1987) 39.

[3] C. Tricard, M.H. Salagoïty, P. Sudraud, Connaiss Vigne Vin 21 (1987) 33.

[4] C. Viriot, A. Scalbert, C. Lapierre, M. Moutonet, J. Agric. Food Chem. 41 (1993) 1872.

[5] P. Chatonnet, I. Cutzach, M. Pons, D. Dubordieu, J. Agric. Food Chem. 47 (1999) 4310.

[6] F. Sarni, M. Moutounet, J.L. Puech, P. Rabier, Holzforschung 44 (1990) 461.

[7] R. Giménez Martínez, H. López Gibb-Serrana, M. Villalón Mir, J. Quesada Granados, M.C. López Martínez, Am. J. Enol. Vitic. 47 (1996) 441.

[8] I. Cutzach, P. Chatonnet, R. Henry, D. Dubordieu, J. Agric. Food Chem. 45 (1997) 2217.

[9] I. Cutzach, P. Chatonnet, R. Henry, D. Dubordieu, J. Agric. Food Chem. 47 (1997) 1663. 
[10] J. González-Rodríguez, P.M. Pérez-Juan, M.D. Luque de Castro, Chromatographia (In Press).

[11] Patent application $\mathrm{N}^{\mathrm{o}}$ P200202467. Spanish Office of Patent and Marks. Science and Technology Ministry.

[12] R.H. Perry, D.W. Green, J.O. Mahoney, in: Perry's Chemical Engineers'Handbook, $6^{\text {th }}$ Edn., McGraw-Hill, New York, 1984, Vol.1. 
